\title{
Patterns of Meiotic Recombination on the Long Arm of Human Chromosome 21
}

\author{
Audrey Lynn, ${ }^{1}$ Carl Kashuk, ${ }^{1,6}$ Michael B. Petersen,, ${ }^{2,3}$ Jeffrey A. Bailey, ${ }^{1}$ \\ David R. Cox ${ }^{4}$ Stylianos E. Antonarakis, ${ }^{5}$ and Aravinda Chakravarti ${ }^{1,6,7}$ \\ ${ }^{1}$ Department of Genetics and Center for Human Genetics, Case Western Reserve University and University Hospitals of \\ Cleveland, Cleveland, Ohio 44106, USA; ${ }^{2}$ Department of Genetics, Institute of Child Health, Athens GR-11527, Greece; \\ ${ }^{3}$ Department of Medical Genetics, The John F. Kennedy Institute, Danish Center for Human Genome Research, Glostrup \\ DK-26000, Denmark; ${ }^{4}$ Department of Genetics and Stanford Human Genome Center, Stanford University, Stanford, \\ California, USA; ${ }^{5}$ Department of Medical Genetics, University of Geneva Medical School, Geneva 4CH-1211, Switzerland
}

\begin{abstract}
In this study we quantify the features of meiotic recombination on the long arm of human chromosome 21 . We constructed a 67.3-centimorgan (cM) high-resolution, comprehensive, and accurate genetic linkage map of chromosome 21q using 187 highly polymorphic markers covering almost the entire long arm; 46 loci, consisting of mutually recombining marker sets, were ordered with greater than 1000:1 odds and with average interlocus distance of $1.46 \mathrm{cM}$. These markers were used to accurately identify all exchanges in 186 female and 160 male meioses and to show (1) significant excess of recombination in female versus male meioses, (2) an overall decline in female:male recombination between the centromere and the telomere, (3) greater positive chiasma interference in male than in female meioses, and (4) lack of correlation between exchange frequency and parental age. By comparing the genetic map with the 2lq sequence map, we show a general trend of increasing male, but near-constant female, recombination versus physical distance across 2lq, explaining the gender-specific recombination effect. The recombination rate varies considerably between genders across $21 \mathrm{q}$ but is the greatest (eightfold) in the pericentromeric region, with a rate of approximately $250 \mathrm{~kb} / \mathrm{cM}$ in females and approximately $2125 \mathrm{~kb} / \mathrm{cM}$ in males. We used information on the locations of all exchanges to construct an empirical map function that confirms the statistical findings of positive interference. These analyses reveal that occurrence of recombination on 21q is not only gender-specific but also region-specific and that recombination suppression at the centromere is not universal. We also find evidence that male exchange location is highly correlated with gene density.
\end{abstract}

There is a widespread, and correct, notion that genetic mapping of the human genome, as a prelude to genome sequencing, is now complete (NIH/CEPH Collaborative Mapping Group 1992; Collins et al. 1998). Existing human linkage maps are the most developed of any eukaryote, despite the refractory nature of using humans for genetic studies. Such maps have several thousand mapped markers and have been invaluable in the positional cloning of genes underlying Mendelian phenotypes. Nevertheless, linkage maps have many additional genetic uses, the most important of which is in understanding recombination in meiosis.

The central feature of genetic transmission in sexually reproducing eukaryotes is meiosis, an evolutionary invention by which a greater proportion of extant genetic diversity is exposed to natural selection. Almost all that we know of human meiosis has arisen either from cytogenetic studies, primarily in the male,

\footnotetext{
6Present address: McKusick-Nathans Institute for Genetic Medicine, Johns Hopkins University, Baltimore, MD 21287, USA. ${ }^{7}$ Corresponding author.

E-MAIL axc39@po.cwru.edu; FAX (216)-368-5857.

Article and publication are at www.genome.org/cgi/doi/10.1101/ gr.138100.
}

that have documented the numbers, locations, and mutual relationships between chiasmata (e.g., Laurie and Hulten 1985), or extrapolations from the observations of meiosis in other organisms (reviewed in Hunt and LeMaire-Adkins 1998). However, human meiosis can also be examined by using transmission of genetic markers within families. These latter studies usually allow (1) an independent examination of meiosis, (2) examination of gender differences in meiosis, the timing and period of which are vastly different in males and females, and (3) comparative analysis to detect differences, if any, between cytogenetic data on preselection gametes and genetic transmission data on postselection zygotes. Nevertheless, cytogenetic studies have established that the general features of human recombination include the occurrence of an obligatory chiasmata on each chromosome arm (Hulten 1974), its variation across the chromosome, with centromeric and telomeric regions having fewer and greater than an average number of exchanges, respectively (Hulten 1974), and that physical size of a chromosomal arm is the strongest, but not the absolute, determinant of recombination frequency (Laurie and Hulten 1985). 
These details can now be examined directly from human genetic marker data.

The essence of genetic mapping is that recombination frequency is dependent on distance between markers, the markers being variants used to detect exchanges without influencing them (see Chakravarti and Lynn 1999). However, the distance involved is not necessarily the physical amount of DNA, because, within genomes, there is great discrepancy between recombination frequency at centromeres and telomeres (Rouyer et al. 1990; Jackson et al. 1996; Mahtani and Willard 1998). Further, at the genome level, different species (such as the human and the mouse) can show a twofold difference in recombination frequency with a near-identical DNA content (Weissenbach et al. 1992; Copeland et al. 1993). Consequently, the DNA sequence itself can regulate recombination. Moreover, epigenetic factors, including DNA modification, chromatin structure, and replication timing may all affect exchange frequency (see Nicolas 1998). Therefore, although physical DNA length is one arbiter of recombination frequency, the actual rate can be influenced both by specific sequences and modifications of the sequence. An ultimate aim of human genetics is to correlate the numbers and locations of exchanges in human meioses with genome organization. This latter study requires details on the patterns of human recombination at a resolution well above that provided by cytogenetic investigations; genetic marker transmission data can fill this need. We report here these patterns of exchanges on human chromosome 21q and how these might relate to the genomic sequence of $21 \mathrm{q}$ (Hattori et al. 2000).

Several studies have constructed meiotic maps of human chromosome 21q, either using the Centre d'Etude du Polymorphisme Humain (CEPH) reference pedigrees (e.g., Warren et al. 1989; Petersen et al. 1991; McInnis et al. 1993; Dib et al. 1996; Broman et al. 1998 ) or the Venezuelan reference kindred (Tanzi et al. 1988, 1992). The chief drawbacks to these maps are threefold: (1) The data have not been assembled into a single map, (2) the maps do not cover the entire long arm of chromosome 21, and (3) recombinants on individual chromosomes have not been studied by considering chromosomal coverage. The present study has reconstructed a single 21q linkage map based on all available microsatellite genetic marker data from the CEPH kindreds, extensively checked and validated all marker data, and added additional loci to increase chromosomal coverage. This last aspect is critical be- cause reduced chromosomal coverage by markers reduces the apparent number of exchanges and gives a false estimate of exchange frequency and chiasma interference. We used the meiotic data on chromosome 21q, the chromosome with the largest number of informative human meioses studied to date, to quantify the patterns of recombination across the chromosome arm in males and females, and as a function of physical distance and parental age.

\section{RESULTS}

\section{Genetic Linkage Map}

The comprehensive genetic linkage map of human chromosome 21 was constructed using an average of 207 (range 38-559) informative meioses per marker from an average of 18 (range 2-40) CEPH families. The map consists of 150 unique, mutually recombining loci of which 46 marker sets could be assigned to unique locations with odds of 1000:1 or better (Fig. 1; Table 1). The details on the families examined, markers used, and the complete genotype data are summarized in Appendices I and II; the data are available at chaklab.cwru.edu/chrom21/chrom21.html. We relied on the use of microsatellite markers only because these data were extensively rechecked by the relevant investigators. The genetic map in female and male meiosis is $80.1 \mathrm{cM}$ and $54.3 \mathrm{cM}$, respectively, so that, on average, there is one exchange per meiosis in either gender. The 46 loci mapped at 1000:1 odds or better define an average interval size of $1.74 \mathrm{cM}$ (range $0.0-5.7 \mathrm{cM}$ ) on the female map and $1.19 \mathrm{cM}$ (range $0.0-8.9 \mathrm{cM}$ ) on the male map; the sex-averaged interval size is $1.46 \mathrm{cM}$ (range $0.3-4.5 \mathrm{cM}$ ). Based on the recently available genomic sequence of 21q (Hattori et al. 2000), we estimate the distance between the spanning markers to be $33,090 \mathrm{~kb}$ (Table 1); the average physical resolution is thus $<720 \mathrm{~kb}$. In addition, the most distal marker, D21S1446, is $82 \mathrm{~kb}$ from the telomeric end, whereas the most proximal marker, D21S215, is $60 \mathrm{~kb}$ from a centromeric $\alpha$-satellite array. The true distance to the centromere cannot be judged from mapping data because the centromere is defined by function. Nevertheless, the distance to the centromere may be greater because the proximal sequence terminates at the start of an $\alpha$-satellite array. Genetic analysis using ovarian teratomas maps D21S215 to $<5 \mathrm{cM}$ of the centromere (A. Chakravarti, unpubl.). Consequently, the current genetic map covers the entirety of $21 \mathrm{q}$.

The investigation of the recombination features of

Figure 1 Genetic linkage map of human chromosome 21q. The comprehensive 21q genetic linkage map with markers mapped at odds of 1000:1 or greater is depicted on the left, with sex-averaged intermarker distances in cM. Additional loci are shown in their 1000:1 odds location to the right of the map, with the most likely interval indicated by the thickest bar. Markers indicated in italics represent known expressed sequences; the remainder are anonymous sequences. Marker names followed by an asterisk $\left(^{*}\right)$ indicate a haplotyped megalocus, as defined in the Methods. 


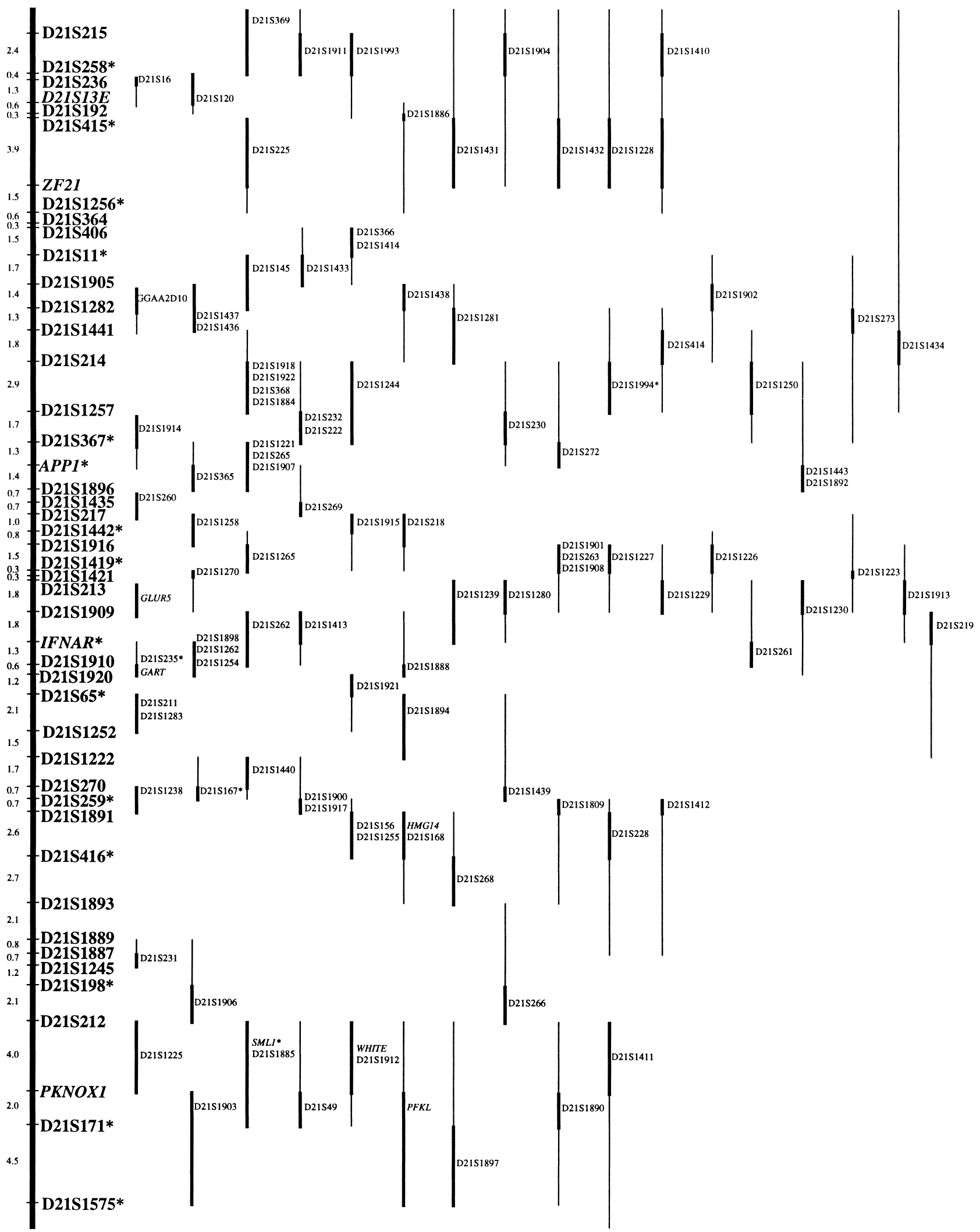


Table 1. Intermarker Genetic and Physical Map Distances on 21q

\begin{tabular}{|c|c|c|c|c|c|}
\hline \multirow[b]{2}{*}{ Locus $^{a}$} & \multicolumn{5}{|c|}{ Intermarker map distances ${ }^{b}$} \\
\hline & $\begin{array}{c}\text { female } \\
\text { cM }\end{array}$ & $\begin{array}{l}\text { male } \\
\mathrm{cM}\end{array}$ & $\begin{array}{c}\text { sex-avg. } \\
\text { cM }\end{array}$ & kb & $\mathbf{c R}$ \\
\hline \multicolumn{6}{|l|}{ D21S215 } \\
\hline D21S258 & 4.1 & 0.9 & 2.4 & 831 & \\
\hline D21S408 & 0.0 & 0.0 & 0.0 & 58 & \\
\hline D21S236 & 0.7 & 0.0 & 0.4 & 181 & 9 \\
\hline D21S13E & 2.6 & 0.0 & 1.3 & 591 & 40 \\
\hline D21S192 & 1.2 & 0.0 & 0.6 & 327 & \\
\hline D21S1231 & 0.6 & 0.0 & 0.3 & 43 & \\
\hline D21S415 & 0.0 & 0.0 & 0.0 & 16 & 14 \\
\hline D21S1234 & 0.0 & 0.0 & 0.0 & 1 & \\
\hline D21S172 & 0.0 & 0.0 & 0.0 & 95 & \\
\hline ZF21 & 5.7 & 2.1 & 3.9 & 2130 & \\
\hline D21S1256 & 3.1 & 0.0 & 1.5 & 255 & 82 \\
\hline D21S409 & 0.0 & 0.0 & 0.0 & 217 & \\
\hline D21S364 & 1.2 & 0.3 & 0.6 & 44 & \\
\hline D21S406 & 0.5 & 0.0 & 0.3 & 97 & 8 \\
\hline D21S1899 & 2.8 & 0.0 & 1.5 & 388 & 42 \\
\hline D21S11/D21S11A/D21S11B & 0.0 & 0.0 & 0.0 & 487 & \\
\hline D21S1905 & 3.4 & 0.0 & 1.7 & 390 & 10 \\
\hline D21S1282 & 3.5 & 0.0 & 1.4 & 658 & \\
\hline D21S1441 & 3.4 & 0.0 & 1.3 & 642 & \\
\hline D21S214 & 0.0 & 1.7 & 1.8 & - & \\
\hline D21S1257 & 4.9 & 0.0 & 2.9 & 2482 & 123 \\
\hline D215367 & 0.0 & 4.6 & 1.7 & 765 & 83 \\
\hline D21S1264 & 0.0 & 0.0 & 0.0 & 181 & \\
\hline D21S210 & 2.2 & 0.4 & 1.3 & 841 & \\
\hline D21S221 & 0.0 & 0.0 & 0.0 & 164 & \\
\hline APP13 & 0.0 & 0.0 & 0.0 & 553 & \\
\hline D21S1253 & 0.0 & 0.0 & 0.0 & 117 & \\
\hline APP1 & 0.0 & 0.0 & 0.0 & 105 & 61 \\
\hline D21S1896 & 2.6 & 0.0 & 1.4 & 285 & 89 \\
\hline D21S1435 & 0.0 & 1.5 & 0.7 & 25 & 3 \\
\hline D21S217 & 1.3 & 0.0 & 0.7 & 570 & 12 \\
\hline D21S1442/D21S1442B & 2.4 & 0.0 & 1.0 & 400 & 15 \\
\hline D21S1916 & 1.5 & 0.0 & 0.8 & 163 & 15 \\
\hline D21S1419 & 1.5 & 2.0 & 1.5 & 470 & \\
\hline D21S226 & 0.0 & 0.0 & 0.0 & - & \\
\hline D21S1421 & 0.6 & 0.0 & 0.3 & 1264 & \\
\hline D215213 & 0.6 & 0.0 & 0.3 & 483 & 111 \\
\hline D21S1909 & 0.9 & 1.7 & 1.8 & 1333 & 74 \\
\hline D21S223 & 0.0 & 3.5 & 1.8 & 708 & 51 \\
\hline D21S224 & 0.0 & 0.0 & 0.0 & 615 & \\
\hline IFNAR & 0.0 & 0.0 & 0.0 & 861 & \\
\hline D21S216 & 0.0 & 0.0 & 0.0 & - & \\
\hline D21S1910 & 2.3 & 0.7 & 1.3 & 233 & 111 \\
\hline D21S1920 & 0.6 & 0.7 & 0.6 & 747 & 92 \\
\hline D21S65 & 0.6 & 1.5 & 1.2 & 392 & \\
\hline D21S1895 & 0.0 & 0.0 & 0.0 & 262 & 20 \\
\hline D21S1252 & 5.5 & 0.0 & 2.1 & 1476 & 79 \\
\hline $\mathrm{D} 21 \mathrm{~S} 1222$ & 0.2 & 1.3 & 1.5 & 101 & \\
\hline D215270 & 2.7 & 1.2 & 1.7 & 903 & 55 \\
\hline D21S259 & 0.0 & 1.2 & 0.7 & 618 & 60 \\
\hline D21S1883 & 0.0 & 0.0 & 0.0 & 50 & \\
\hline D21S1891 & 0.0 & 1.2 & 0.7 & 923 & \\
\hline D21S1246 & 1.8 & 3.4 & 2.6 & 447 & 155 \\
\hline D21S416 & 0.0 & 0.0 & 0.0 & 76 & \\
\hline D21S1893 & 2.6 & 2.4 & 2.7 & 409 & 21 \\
\hline $\mathrm{D} 21 \mathrm{~S} 1889$ & 2.6 & 1.9 & 2.1 & 468 & \\
\hline D21S1887 & 1.4 & 0.0 & 0.8 & 390 & 46 \\
\hline $\mathrm{D} 21 \mathrm{~S} 1245$ & 1.4 & 0.0 & 0.7 & 198 & \\
\hline D21S1235 & 1.2 & 1.2 & 1.2 & 52 & \\
\hline D21S198 & 0.0 & 0.0 & 0.0 & 10 & \\
\hline D21S1224 & 0.0 & 0.0 & 0.0 & 253 & 76 \\
\hline D21S1260 & 0.0 & 0.0 & 0.0 & 68 & 12 \\
\hline
\end{tabular}


Table 1. (Continued)

\begin{tabular}{|c|c|c|c|c|c|}
\hline \multirow[b]{2}{*}{ Locus $^{\mathrm{a}}$} & \multicolumn{5}{|c|}{ Intermarker map distances ${ }^{\mathbf{b}}$} \\
\hline & $\begin{array}{c}\text { female } \\
\text { cM }\end{array}$ & $\begin{array}{c}\text { male } \\
\mathrm{cM}\end{array}$ & $\begin{array}{c}\text { sex-ave. } \\
\text { cM }\end{array}$ & kb & CR \\
\hline D21S212 & 2.6 & 1.6 & 2.1 & 324 & 23 \\
\hline PKNOX1 & 0.0 & 6.8 & 4.0 & 1308 & 244 \\
\hline D21S171 & 3.3 & 1.5 & 2.0 & 1506 & \\
\hline D21S170 & 0.0 & 0.0 & 0.0 & 0.1 & \\
\hline D21S1261 & 0.0 & 0.0 & 0.0 & 144 & 172 \\
\hline D21S2058 & 0.0 & 8.9 & 4.5 & 1829 & \\
\hline D21S1575 & 0.0 & 0.0 & 0.0 & 68 & \\
\hline D21S1446 & 0.0 & 0.0 & 0.0 & 1 & \\
\hline
\end{tabular}

chromosome 21 required a linkage map that was highly accurate in both the order of the loci and the estimation of the distances between the loci. To this end, a number of steps were taken to verify the accuracy of the map presented here. The final comprehensive map order was supported by likelihood analysis of permutations of all four, five, and six consecutive markers. Final validation of undetected genotyping errors was performed by a drop-one-locus analysis (Lasher et al. 1991). Specifically, each nonterminal locus was excluded from the map and overall map length was reestimated. In the presence of undetected genotyping errors, the difference in total map length between the fixed terminal loci, between the overall map and the reestimated map, is positive and equals twice the error rate; random fluctuations lead to either a positive or negative difference. Any markers that were outliers were removed and map construction was reinitiated using the final comprehensive map minus these error-prone loci. The largest deviation from the total map length was $1.26 \mathrm{cM}$ for the female map and 0.72 cM for the male map. These values represent reductions of just $1.6 \%$ and $1.3 \%$, respectively, of the total length of the female and male genetic maps, indicating the overall accuracy of the genotype data reported here.

\section{Gender Differences in Recombination}

The female genetic map, at $80.1 \mathrm{cM}$, is $46 \%$ longer than the male map of $54.3 \mathrm{cM}$. A likelihood ratio test, comparing the map with sex-averaged recombination $\left(\log _{\mathrm{e}}\right.$ likelihood $=-1674.7$ ) to that with sex-specific recombination ( $\log _{\mathrm{e}}$ likelihood $\left.=-1596.5\right)$, provided highly significant statistical support $\left(p=2 \times 10^{-14}\right.$ at 45 degrees of freedom [d.f.]) in favor of gender differences. Moreover, there was overwhelming support for variation in the sex-difference rate across the map $\left(p=2 \times 10^{-5}\right.$ at 1 d.f.) because a model assuming a
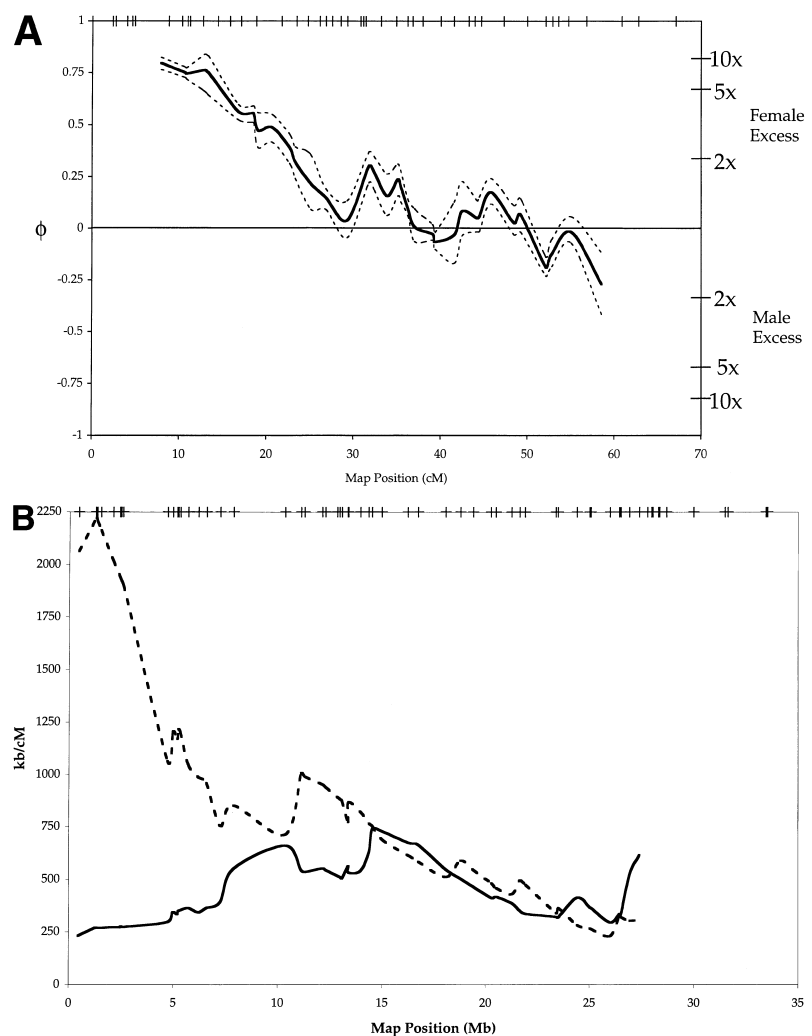

Figure $2(A)$ Gender differences in recombination on human chromosome $21 \mathrm{q}$. A normalized statistic quantifying the difference $(\varphi)$ in recombination rates between female and male meioses ( $\mathrm{Y}$-axis) is plotted against the midpoint of each interval across the sex-averaged genetic map ( $\mathrm{X}$-axis). One standard deviation unit on either side of $\varphi$ is also plotted. The tick marks at the top of the figure represent the location of the markers on the sexaveraged linkage map. (B) Recombination vs. physical distance on human chromosome $21 \mathrm{q}$. Estimates of $\mathrm{kb} / \mathrm{cM}$ (Y-axis) are plotted against the midpoint of each interval across the sequence map (X-axis); female and male values are represented by solid and dashed lines, respectively. The tick marks at the top of the figure represent the physical location of the markers used. 
constant sex-difference in recombination ( $\log _{\mathrm{e}}$ likelihood $=244.4$ ) across the chromosome fit poorly in comparison to a model with variation in the gender effect $\left(\log _{\mathrm{e}}\right.$ likelihood $\left.=260.4\right)$. To quantify this pattern of gender-specific recombination, we plotted the normalized statistic $\varphi$ (see Methods) across the sexaveraged map. The gender-effect map shown in Figure $2 \mathrm{~A}$ also shows the variation in the estimated $\varphi$ values, independently confirming that the pattern of sexdifference on $21 \mathrm{q}$ is statistically significant and varies by chromosomal location. Although, overall, female recombination is approximately 1.5 -fold greater than in males, the dominant significant trend is that female, compared with male, recombination is greatest near the centromere and declines across the chromosome arm. These analyses show that female recombination exceeds male rates in more than $85 \%$ of $21 q$; a large fivefold female excess is localized to the pericentromeric $25 \%$ of $21 \mathrm{q}$, whereas in the most telomeric region, male recombination is greater than female rates by approximately 1.8 -fold.

\section{The Relationship between Genetic and Physical Maps}

The gender effect on recombination, particularly the female:male decline across $21 \mathrm{q}$, is intriguing, but, being a relative test, does not clarify whether the decline is female-specific or male-specific or both. To study this latter behavior, we computed recombination rate as a function of physical distance, because this analysis would elucidate whether the effects were global or local. The recent publication of the DNA sequence for human chromosome 21 (Hattori et al. 2000) allowed us to estimate directly the physical distance between polymorphic loci. The 1000:1 odds or greater common map had 68 loci (including haplotyped markers) spanning the entire q-arm from D21S215 to D21S1446. The markers tested and their intermarker distances in $\mathrm{kb}$ are provided in Table 1 . The nested female genetic, male genetic, and physical maps had distances of 80.1 $\mathrm{cM}, 54.3 \mathrm{cM}$, and 33,632 kb, respectively. Thus, the physical distance per unit map distance is $420 \mathrm{~kb} / \mathrm{cM}$ in females and $620 \mathrm{~kb} / \mathrm{cm}$ in males. For the human genome the standard assumption is a rate of $1000 \mathrm{~kb} /$ cM (Weissenbach et al. 1992). Thus, chromosome 21q has an overall recombination rate $(500 \mathrm{~kb} / \mathrm{cM})$ that is double the human genome average.

Figure 2B shows that, for either sex, recombination does not occur at a uniform velocity per unit physical distance across 21q. Male recombination per physical distance was lowest $(-2125 \mathrm{~kb} / \mathrm{cM})$ in the pericentromeric region and showed a consistent pattern of increase toward the telomere $(\sim 400 \mathrm{~kb} / \mathrm{cM})$. Female recombination per physical distance, on the other hand, showed some fluctuation but was overall much more constant across the $21 \mathrm{q}$ arm $(\sim 600 \mathrm{~kb} / \mathrm{cM})$. The major female:male differences on $21 \mathrm{q}$ meioses arise from the proximal third of the chromosome arm; at the centromeric end this difference is approximately eightfold $(\sim 2125 \mathrm{~kb} / \mathrm{cm}$ in males; $250 \mathrm{~kb} / \mathrm{cM}$ in females). The male and female patterns shown in Figure $2 \mathrm{~B}$ are entirely consistent with the sex difference graph in Figure 2A and provide an explanation for the sex-difference pattern in meiosis, which is largely dominated by the male-specific effect.

\section{Interference}

A well-known feature of meiosis, universal in all species, is the nonrandom distribution of exchanges along a chromosome arm. This nonrandom pattern may arise either in the number of exchanges or from their placement-chiasma interference, in which the occurrence of one recombination event limits the occurrence of a second event in its vicinity (Muller 1916). If crossovers can occur anywhere along the chromosome bivalent with equal probability, then the map distances between crossovers are exponentially distributed and the number of chiasmata are Poisson distributed with mean equal to twice the map distance in Morgans (Haldane 1931). The distribution of the number of exchanges on gametes is also Poisson but with mean equal to map distance (see Methods). We considered all 21q gametes, classified by parental origin, that had a density of informative markers sufficient to ensure that all exchanges could be detected at $90 \%$ or better probability (see Methods). In the absence of such a criterion, we would observe fewer exchanges than the actual number and produce a false impression of departure from expectations. The recombination data, together with the Poisson expectations, are shown in Table 2. Tests of $\chi^{2}$ goodness-of-fit show that the null Poisson hypothesis can be strongly rejected. In both sexes, there is a deficiency of zero exchanges and an excess of single exchanges. For double, or greater, exchanges, male meioses show a much stronger deficiency than do female meioses. The reduction in number of double or greater exchanges is consistent with positive interference. Because the nonrandomness, which can be quantified by $\mathrm{I}=\chi^{2} /$ number of meioses, is less pronounced in female $(I=0.04)$ than in male $(\mathrm{I}=0.17)$ meioses, the degree of nonrandomness (interference) is greater in male than in female meioses.

Chiasmata are the visibly observable connections between homologous chromosomes that can be observed in cells entering metaphase (Jannsens 1909) and presumably represent the location of exchanges or recombination events. For male meioses, chiasma counts from sperm studies can also be used to predict the number of exchanges, under positive interference (Laurie and Hulten 1985). These expectations from cytogenetic studies were compared with our genetic observations; as shown in Table 2, the fit is excellent. Thus, the genetic and cytogenetic data are concordant

\section{Genome Research}


Table 2. Number of Exchanges in Female and Male Meioses for 21q

\begin{tabular}{|c|c|c|c|c|c|}
\hline \multirow{3}{*}{$\begin{array}{l}\text { No. of } \\
\text { exchanges }\end{array}$} & & & \multicolumn{3}{|c|}{ Male meioses } \\
\hline & \multicolumn{2}{|c|}{ Female meioses } & \multirow[b]{2}{*}{ observed } & \multirow{2}{*}{$\begin{array}{l}\text { expected } \\
\text { (Poisson) }\end{array}$} & \multirow{2}{*}{$\begin{array}{c}\text { expected }^{b} \\
\text { (Laurie and } \\
\text { Hulten 1985) }\end{array}$} \\
\hline & observed & expected (Poisson) ${ }^{a}$ & & & \\
\hline 0 & 80 & 93 & 77 & 92 & 78 \\
\hline 1 & 83 & 64 & 78 & 51 & 79 \\
\hline $2+$ & 23 & 29 & 5 & 17 & 3 \\
\hline Total & 186 & 186 & 160 & 160 & 160 \\
\hline $\begin{array}{l}\chi^{2}, 1 \text { d.f. } \\
p \text {-value }\end{array}$ & & $\begin{array}{l}7.9 \\
0.005\end{array}$ & & & $\begin{array}{l}1.4 \\
0.244\end{array}$ \\
\hline
\end{tabular}

and do not show major differences between recombination studied in preselection gametes as compared with postselection zygotes.

Laurie and Hulten (1985) also showed positive interference by studying the locations of chiasmata; i.e., two 21q chiasmata did not occur close to one another. We used the genetic data to study the distribution of the distances between the double exchanges. The observations were compared with expectations derived from the distance between two randomly chosen single exchanges. Rather than comparisons based on the incorrect theoretical model (see results above) in which crossovers can occur anywhere with equal probability, we used the observed data on singleton events to simulate distances between doubles. We next compared the observed and simulated cumulative frequency distributions and found that the female distribution is nonrandom with increased distance between double exchanges $(p=0.0001)$, but that the male distribution is within random expectations $(p=0.99)$, most likely because only five double exchanges were observed. Thus, the effects of positive interference are such that, in female meioses, both the number and locations of exchanges are nonrandom across 21q, but in male meioses only the number of exchanges can be shown to be nonrandom across $21 \mathrm{q}$. Thus, the genetic features of interference may be different in males and females.

\section{Recombination Versus Parental Age}

There has been a long-standing notion in human genetics that recombination may be significantly affected by parental age (Elston et al. 1976); this is particularly so for 21q. Indeed, Tanzi et al. (1992) have previously shown a decrease in recombination with increasing maternal age, in both the terminal and pericentromeric regions of $21 \mathrm{q}$ using the Venezuelan Ref- erence Pedigree. We reevaluated this effect within the CEPH families by stratifying each exchange by both gender and age of the parent (Table 3). There were 299 CEPH offspring for whom we had dates of birth for both parents and offspring; of these, 159 maternal and 150 paternal meioses had $90 \%$ or better chromosomal coverage. The distribution of recombination events as a function of three age groups ( $<25$ years, 25-35 years, $>35$ years) was not significantly different from each other in either gender $(p=0.40$ and 0.99 for the female and male chromosomes, respectively). The chromosomes were also grouped by the number of observed exchanges, and the variation within and between the parental age classes was compared using ANOVA. This analysis showed no significant difference in maternal ( $p=0.88)$ or paternal $(p=0.84)$ transmissions, respectively. Thus, parental age is not a major determinant of

Table 3. Distribution of Exchanges on Chromosome 21q Stratified by Parental Origin and Age

\begin{tabular}{|c|c|c|c|c|c|c|}
\hline \multirow[b]{3}{*}{$\begin{array}{l}\text { No. of } \\
\text { exchanges }\end{array}$} & \multicolumn{3}{|c|}{ Female meioses } & \multicolumn{3}{|c|}{ Male meioses } \\
\hline & \multicolumn{3}{|c|}{ age (yr) } & \multicolumn{3}{|c|}{ age (yr) } \\
\hline & $<25$ & $25-35$ & $>35$ & $<25$ & $25-35$ & $>35$ \\
\hline 0 & 22 & 40 & 7 & 16 & 43 & 15 \\
\hline 1 & 18 & 42 & 9 & 14 & 42 & 16 \\
\hline $2+$ & 9 & 8 & 4 & 1 & 2 & 1 \\
\hline Total & 49 & 90 & 20 & 31 & 87 & 32 \\
\hline $\begin{array}{l}\chi^{2}, 4 \text { d.f. } \\
p \text {-value }\end{array}$ & & $\begin{array}{c}4.1 \\
0.40\end{array}$ & & & $\begin{array}{c}0.3 \\
0.99\end{array}$ & \\
\hline
\end{tabular}

The observations in Table 2 were reclassified by parental age (yr) and contingency analysis used to test for age-related trends. 
recombination for human chromosome 21q. The differences between these results and those of Tanzi et al. (1992) may arise from population differences or the use of a larger sample size covering a greater portion of 21q.

\section{Empiric Map Function}

Construction of human linkage maps has always required the explicit use of the Kosambi (1944) mapping function; however, the implicit assumption of the specific level of chiasma interference has never been tested. Fortunately, the accuracy and resolution of the current genetic map for chromosome 21q allows an empirical map function to be estimated in the absence of assumptions. Specifically, we computed this function by considering all possible pairs of markers on the 1000:1 odds map; i.e., 1004 comparisons for maternal meioses and 1016 for male meioses, for each of which we had the estimated recombination fraction and the derived map distance as a sum of all adjacent map intervals. Figure 3 shows this map function, with smoothed values, separately for female and male maps. As expected, the Haldane map function shows excellent fit for map distances less than $20 \mathrm{cM}$. For values greater than $20 \mathrm{cM}$, however, there is direct evidence of chiasma interference at approximately the Kosambi level. Also, the male map shows a greater departure from the Haldane map function than does the female map. The lower recombination rate observed in males may result from stronger effects of interference acting in the male genome than in the female genome.

\section{DISCUSSION}

The object of this study was to assemble all of the known microsatellite marker genotype data in the $\mathrm{CEPH}$ reference pedigrees on human chromosome $21 \mathrm{q}$

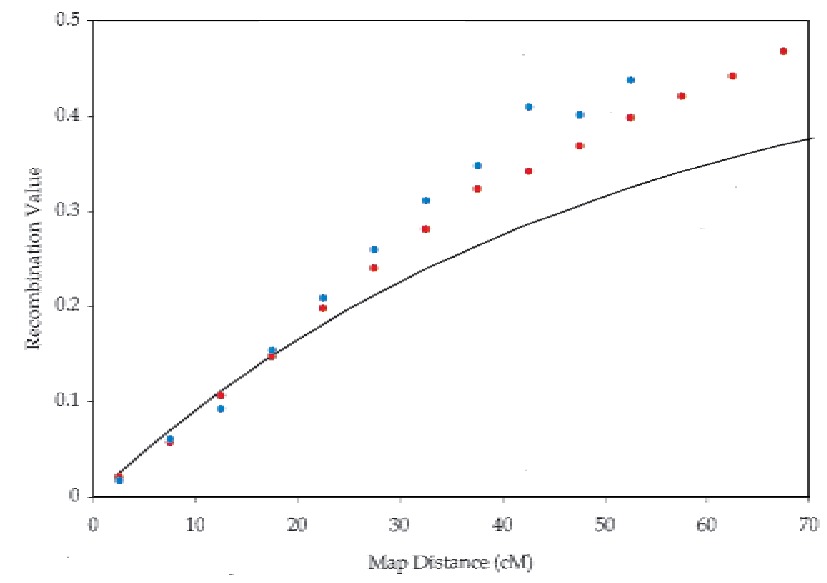

Figure 3 Gender-specific empiric map functions for human chromosome $21 \mathrm{q}$. Estimated recombination values and map distances are shown for female and male meioses. The red and blue dots represent results from female and male meioses, respectively; the black line is the Haldane map function. to construct a meiotic map. The error checking of genotypes and the use of a mapping algorithm that was intended to prevent the inclusion of markers likely to contain genotyping errors have led to a highly accurate and high-resolution map. Consequently, the sex-averaged length of the current $21 \mathrm{q}$ map is $67.3 \mathrm{cM}$, which is comparable to or shorter than previously published 21q linkage maps despite the addition of many more markers. Table 4, which summarizes previous 21q genetic maps, shows how the mapping of this chromosome has evolved, primarily the recognition of considerable genotyping errors in the early days of map construction. There is colinearity of common marker loci for all of the maps listed. In addition, comparison of our marker order to published physical maps, including the genomic sequence, confirms the order of $>95 \%$ of markers (www.ncbi.nlm.nih.gov; www.shgc.stanford.edu; www-genome.wi.mit.edu).

The accuracy and density of the $21 \mathrm{q}$ map we present has also allowed us to investigate the recombination features of chromosomes 21 at a resolution previously not attained. The primary features of recombination on 21q suggest a difference in many aspects of meiosis between males and females. Although recombination is overall more frequent in females than in males, the recombination rate is roughly constant across $21 \mathrm{q}$ in female meioses but shows a strong suppression effect at the centromeric end in male meioses. Thus, the 21q gender difference in meiosis is largely a property of male recombination. Chiasma interference can be shown in both genders for 21q; however, the effect is more pronounced in males than in females. This interference phenomenon is restricted not only to the less than expected number of exchanges but also in the greater than expected distance between double exchanges. We have also constructed, for the first time, an empirical map function of this chromosome that summarizes each of the above genetic effects. Finally, we fail to show any effect of parental age on recombination frequency.

The two major findings from this study are the large roles that gender and chromosomal position play on recombination and its features on 21q. The gender effect on recombination frequency is well-known and likely arises from the considerable differences in the timing and duration of events during meiotic prophase in females and males (reviewed in Handel and Eppig 1998). However, this hypothesis necessitates that pachytene, in particular, be longer in the female than in the male. It is not clear that this is true in the human, although in the mouse pachytene is actually longer in the male by at least a few days (see Handel and Eppig 1998). It is also possible that some of the differences arise from the role of the sex chromosomes, from differences in gender-specific trans-acting factors, from differences in chromatin structure during male 
Table 4. Genetic Maps of Chromosome 21q

\begin{tabular}{lcccc}
\hline Study & $\begin{array}{c}\text { No. } \\
\text { mkrs }\end{array}$ & Spanning interval & $\begin{array}{c}\text { Map length } \\
\text { (cM) }\end{array}$ & $\begin{array}{c}\text { Length on } \\
\text { current map }\end{array}$ \\
\hline Tanzi et al. 1988 & 13 & D21S13E-D21S19 & 81 & 59 \\
Warren et al. 1989 & 17 & D21S13E-BCE1 & 121 & 59 \\
Petersen et al. 1991 & 27 & D21S13E/D21S16-COL6A1 & 144 & 59 \\
Tanzi et al. 1992 & 27 & D21S13E-CD18 & 48 & 59 \\
Mclnnis et al. 1993 & 43 & D21S215-D21S171 & 63 \\
Dib et al. 1996 & 61 & D21S1904-D21S1897 & 60 & 64 \\
Broman et al. 1998 & 111 & D21S1911-D21S2058 & 58 & 66 \\
Lynn et al. 2000 & D21S215-D21S1575 & 67 & $(67)$ \\
\hline
\end{tabular}

and female meiosis, or from a combination of multiple factors. For example, in female meiosis, all of the chromosomes participate in recombination and gene transcription; however, in male meioses, the sex chromosomes are primarily absent from these processes (see Handel and Eppig 1998). The X chromosome in spermatocytes is highly methylated, condensed, and transcriptionally inactive, in stark contrast to the transcriptionally active and euchromatic X chromosomes observed in oocytes (Handel and Hunt 1992). It is possible that the $\mathrm{X}$ chromosome contains one or more genes that code for a trans-acting factor(s) that serves to increase or decrease the efficiency of recombination elsewhere in the genome. This hypothesis assumes a baseline rate of recombination in one gender that is then enhanced or suppressed in the other gender because of the presence of this trans-acting factor. The 21q data are compatible with this speculation.

We have also shown stark differences in recombination patterns across different regions of 21q. These differences appear to result largely from male-specific suppression near the centromeric end. Specific DNA sequences could be responsible for these patterns. The 'trans-acting factor hypothesis', outlined above, could be a parsimonious explanation for these findings as well, because the interaction between trans-acting factors with chromosomes could be caused by either an affinity for the direct underlying sequence or the local secondary structure of the DNA.

Open chromatin structure appears to be an important factor in the placement of recombination events, which vary across $21 q$. Studies in yeast have provided a link between sites of recombination and the presence of transcription factors (e.g., HIS4, White et al. 1991, 1992, 1993). Specifically, hotspots of recombination are abolished if certain transcription factors are not present or if binding sites for the transcription factors are mutated. In addition, in Saccharomyces cerevisiae, it appears that double-strand breaks in the promoter regions of genes are the initiating event for recombination, and that open chromatin conformation in these regions is the important feature (Shenkar et al. 1991). Possible explanations for these findings include: early in meiosis chromatin undergoes conformational changes that make it accessible to the double-strand break nuclease; or, the change in chromatin accessibility may be a result of formation of a preinitiating recombination complex at the site where the doublestrand break will subsequently be located (Nicolas 1998). In the human, it has been observed that female chromosomes are approximately 50\% longer than male chromosomes during pachytene, implying a lesscondensed state for the chromatin in female chromosomes (Wallace and Hulten 1985). It is possible that this generalized, less-condensed state of the chromosomes allows for greater opportunity for recombination in females and provides a biological explanation for the weaker effects of interference noted in females for 21q.

A standard assumption in genetics is the repression of recombination at the centromere; this is clearly true for the $\mathrm{X}$ chromosome where this has been studied (Mahtani and Willard 1998). However, the results of 21q suggest that this might not be universal. In the most centromeric interval studied, male and female meioses clearly differ, with female meioses showing the greatest recombination frequency (Fig. 2B). Consequently, either the repression mechanism itself is variable (sequence-dependent?) or our maps do not cover the region in which recombination suppression occurs. Even in the latter case, female meioses recover from the repression differently than males in the vicinity of the 21q centromere.

The genomic sequence of chromosome 21q allows us to investigate whether sequence properties can explain the global recombination effects we have quantified. A simple quantification of the genetic-cumphysical effect of recombination is the frequency of meiosis in the two equal halves of 21q: Females and males show $63 \%$ and $25 \%$, respectively, of all meiotic exchanges in the first half of 21q. We analyzed the density of different classes of repeated sequences (short 
interspersed repeated segments [SINES], long interspersed repeated segments [LINES], long terminal repeats, DNA transposons, and satellite sequences) across the $21 \mathrm{q}$ arm in bins of $400 \mathrm{~kb}$. The major difference was the great preponderance of LINE elements in the first half of $21 \mathrm{q}$ (60\% of the total) and the excess of SINE elements in the second half of $21 \mathrm{q}$ ( $62 \%$ of the total). These differences were expected from previous research (Korenberg and Rykowski 1988); however, they are not a sufficient explanation of the recombination effect in males or females. On the other hand, analyzing the density of genes on $21 \mathrm{q}$ gives a pattern that is highly coincident with the distribution of exchanges in male meioses across $21 \mathrm{q}$ (Fig. 4). These data allow us to propose that recombination on $21 \mathrm{q}$ in males and females may arise from distinct processes. In males, exchange locations are highly dependent on gene density. In females, the pattern is more uniform across the chromosome, suggesting either a different mechanism or the simple accumulation of exchanges in a meiosis that occurs over a much longer time.

It is now well-established that recombination is reduced on nondisjoined chromosome 21s (Warren et al. 1987; Sherman et al. 1991, 1994), specifically be- cause of an increase in chromosomes with zero or one recombination events in mothers of Down syndrome infants (Sherman et al. 1994). It also appears evident that the position of recombination events is important in the correct segregation of chromosome 21 (Lamb et al. 1996, 1997). There is an apparent increase in the rate of distal recombinations in female-derived meiosis I trisomy events for chromosome 21, whereas the female-derived meiosis II trisomy events show an excess of proximal recombination events. Position of recombination also has an effect on proper chromosome segregation in yeast (Ross et al. 1996); however, no mechanism for this is as yet known. The $21 \mathrm{q}$ recombination features we have identified may be useful for the further understanding of this relationship between recombination and nondisjunction of chromosome 21 .

\section{METHODS}

\section{Genetic Markers}

We have maintained a repository for chromosome 21 polymorphic marker genotype data including corrections to genotype data obtained from investigators over time. A total of 187 polymorphic markers were genotyped in $40 \mathrm{CEPH}$ reference

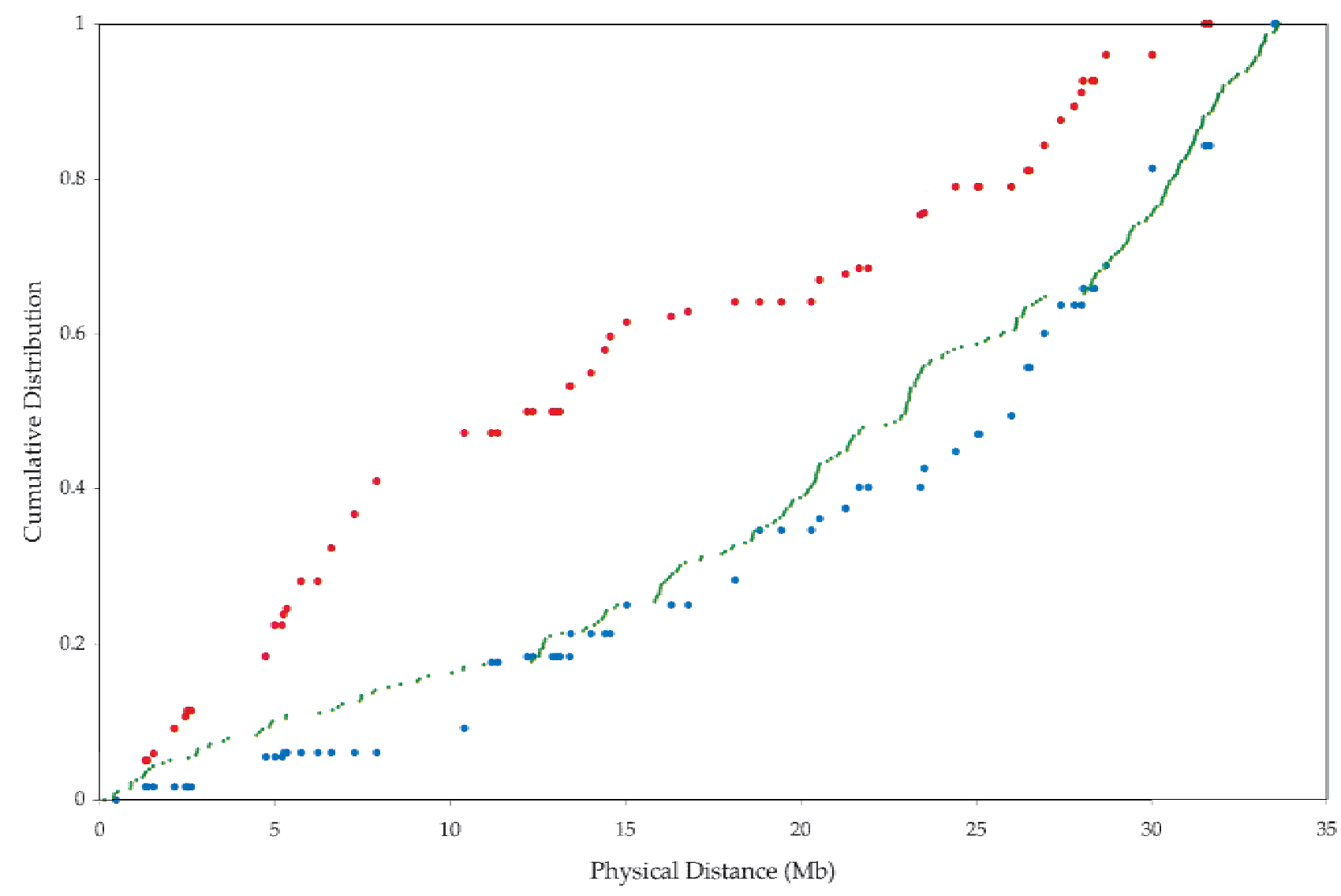

Figure 4 Relationship between recombination and gene density on chromosome $21 \mathrm{q}$. Cumulative frequency of recombination in females (red dots) and males (blue dots) are plotted against the sequence map together with cumulative gene density (green dots). 
pedigrees (Dausset et al. 1990) including grandparents, parents, and at least six offspring. Appendix I (available as an online supplement at www.genome.org) lists each microsatellite marker on which genotype data have been obtained, the polymorphism motif, the number of CEPH families in which the marker was genotyped, the laboratory contributing the genotype data, and a literature citation. The genotypes contributed by each laboratory are identified in the legend to Appendix I; some markers were genotyped by more than one laboratory. Appendix II (available as an online supplement at www.genome.org) provides a summary of the variation features of the polymorphism data. The majority (72\%) of the markers used in this study were dinucleotide repeat markers. The average heterozygosity of all markers was $68 \%$ (range $22-$ $94 \%$ ), but $81 \%$ of the markers had heterozygosity greater than $60 \%$. There was not a significant difference in average heterozygosity between the repeat motifs; however, dinucleotide markers did have, on average, one additional allele than did tri- or tetranucleotide markers (7 vs. 6). The average number of informative meioses examined for each marker was 207 (range 38-559). Genotypes were rigorously examined at numerous stages during map construction through the identification of putative multiple recombination events; all such data were reevaluated or regenotyped by the contributing laboratory and are available at chaklab.cwru.edu/chrom 21 / chrom21.html.

\section{Linkage Map Construction and Validation}

We initially identified all mutually linked loci with no intralocus recombination, which we term megaloci. For six loci (D21S11, D21S167, D21S235, D21S1442, D21S1994, APP), genotypes for multiple distinct polymorphisms within the same locus were haplotyped to create six megaloci. In addition, D21S415 and D21S1234 have been shown to be the same marker (X. Estivill, pers. comm.), as are D21S171 and D21S170. Two-point linkage analysis identified additional groups of markers that showed no recombination with each other but recombined with all other markers not in that group. We constructed a total of 19 megaloci involving a total of 56 markers as follows: (D21S11/D21S11A/D21S11B/ D21S1899), (D21S167/D21S167L/D21S267/ D21S1919), (D21S235/D21S235a/D21S235b/D21S235DB-3/D21S235DB4), (D21S1442/D21S1442B), (D21S1994/D21S1994B), (APP1/ APP13/D21S221 /D21S1253/D21S210), (D21S171/D21S170/ D21S1261), (D21S415/D21S1234/ D21S172/D21S1231), (D21S1575/D21S1446/D21S2058), (D21S65/D21S1895), (D21S198/D21S1224/D21S1235/D21S1260), (D21S258/ D21S408), (D21S367/D21S1264), (IFNAR/D21S223/D21S224/ D21S216), (SML1/D21S1259), (D21S1256/D21S409), (D21S1419/D21S226), (D21S416/D21S1246), and (D21S259/ D21S1883). Thus, there were 150 unique (mutually recombining) loci available for genetic map construction.

The genetic linkage map was constructed by repeatedly using MultiMap (Matise et al. 1994), an automated expert system that uses the likelihood-based analysis program CRIMAP (Lander and Green 1987) and heuristics for map construction. We first constructed a framework map by ranking all markers by their heterozygosity and/or joint-PIC value (Chakravarti 1991), as measures of informativeness, to determine the order in which markers were sequentially added during serial map construction. The most informative marker pair was selected to seed the map such that its pairwise lod score exceeded 3 and recombination fraction lay between 0.10 and 0.20 . Subsequently, markers were added to the map, in decreasing order of informativeness, whenever they could be localized with odds of 1000:1 or greater and had recombination frequency between 0.05 and 0.10 to any marker on the map. At each stage of marker addition, map order was validated by permuting the order of all adjacent locus pairs ("flips-2 analysis"); a new order was accepted only when the likelihood exceeded odds of 1000:1 over the previous order. To reduce the effects of undetected genotyping errors, we excluded markers from consideration whenever their inclusion increased the local map length by more than 10\% (Buetow 1991; Lasher et al. 1991). Finally, we constructed a comprehensive map by adding all other unplaced markers to their 1000:1 odds location, no restrictions being placed on the recombination frequency between markers being added and those on the map. For each marker added, map order was validated by likelihood analysis of all possible permutations of three or more adjacent loci, and choosing orders with likelihoods of 1000:1 or better.

Recombination events (exchanges) on the comprehensive map were identified using the CHROMPIC option from CRI-MAP. All chromosomes showing multiple exchanges were examined to determine how many informative markers contributed to the apparent recombinant(s); all meioses with a single informative marker contributing to a multiple recombination event were reevaluated by the contributing laboratory. Following resolution of the genotypes, the entire mapbuilding algorithm was reinitiated. This process continued until there was a final map in which the markers making up multiple recombination events had all been exhaustively examined and validated.

\section{Quantifying Gender Differences in Recombination}

To quantify gender differences in recombination frequency across the map, a natural statistic is to compare map distances in females $\left(\omega_{\mathrm{f}}\right)$ vs. males $\left(\omega_{\mathrm{m}}\right)$ as a ratio $\left(\omega_{\mathrm{f}} / \omega_{\mathrm{m}}\right)$ for each adjacent marker interval (Broman et al. 1998). However, this statistic is a poor choice for two reasons: (1) ratio statistics can be undefined with positive probability and, therefore, have undesirable statistical properties; (2) marker intervals are of varying size on a map and the accuracy of the estimated ratio depends strongly on the interval size. We propose instead the use of the normalized and standardized gender difference statistic $\varphi$ defined as:

$$
\phi=\frac{\omega_{\mathrm{f}}-\omega_{\mathrm{m}}}{\omega_{\mathrm{f}}+\omega_{\mathrm{m}}} .
$$

$\varphi$, analogous to Yule's association measure, always lies in the range $[-1,+1]$. A relative excess of female (male) recombination provides positive (negative) $\varphi$ values, approaching +1 $(-1)$ with an exaggerated excess of recombination in female (male) meioses. To evaluate the trend in gender difference across the chromosome, we calculate $\varphi$ in overlapping windows of $15 \mathrm{cM}$, comprising multiple adjacent marker intervals, along the length of the chromosome arm. The optimum window size necessary to identify true differences in recombination rates (between $\omega_{\mathrm{f}}=\omega_{\mathrm{m}}$ to $\omega_{\mathrm{f}}=20 \omega_{\mathrm{m}}$ ), while reducing differences caused by random fluctuations, in 100-300 informative meioses, was determined by computer simulation studies to be $\sim 15 \mathrm{cM}$ on the sex-averaged map. This value was determined as the map distance at which $\varphi$ had both the smallest relative bias and standard deviation.

To assess variation around estimated $\varphi$ values, we used the jackknife procedure (Efron 1982). Each of the CEPH fami- 
lies was sequentially removed from the observations, and $\varphi$ was recalculated across the map. The mean and standard deviation of these recomputed values were estimated and are shown in Fig. 2A.

\section{Physical Maps and Quantifying Effects of Physical Distance}

The DNA sequence for the entire chromosome 21q, obtained from the RIKEN Genomic Sciences Center (hgp.gsc.riken. go.jp), consists of four nonoverlapping contiguous sequences comprising $33.6 \mathrm{Mb}(\operatorname{chr} 21 \mathrm{~A}=28,515 \mathrm{~kb}, \mathrm{chr} 21 \mathrm{~B}=219 \mathrm{~kb}$, chr21C $=1278 \mathrm{~kb}, \operatorname{chr} 21 \mathrm{D}=3429 \mathrm{~kb})$ including estimated gap sizes of gap1 $\sim 32 \mathrm{~kb}$, gap2 $\sim 35.4 \mathrm{~kb}$, and gap3 $\sim 22 \mathrm{~kb}$ (Hattori et al. 2000). Nucleotide sequences of 63 of 74 markers from the 1000:1 odds genetic map were obtained from GenBank (www.ncbi.nlm.nih.gov/Genbank/index.html); primer sequences for six additional loci (D21S210, D21S212, D21S214, D21S216, D21S409, and D21S1224) were identified in The Genome Database (GDB: gdbwww.gdb.org/); two additional loci (D21S170 and ZF21) were provided by S. Antonarakis. Physical locations of polymorphisms in three genes (APP, IFNAR, and PKNOX1) on our map were represented through primer sequences identifying the polymorphic site rather than the full-length genomic sequence. Specific sequence for three marker loci (D21S11A, D21S11B, and D21S1442B) could not be obtained, but all these loci occur within a megalocus and so have no effect on the genetic analysis. Nucleotide sequences in FASTA format were masked with RepeatMasker v.3.0 (ftp.genome.washington.edu/RM/ RepeatMasker.html) and used in similarity searches against the entire 21q genomic sequence using BLASTN (Altschul et al. 1990); both masked and unmasked versions of the chromosome 21 sequence were analyzed. We used a threshold of $p<0.01$ in BLASTN analysis: of 71 markers tested, 70 (except D21S214) had $p<0.01$ and 68 of these were colinear with the genetic map. The positions of D21S226 and D21S216 were two and one interval distal to the genetic placement, respectively. For each marker, physical position was computed as the midpoint of the start and end positions of the BLASTN query within the 21q genomic sequence.

A radiation hybrid (RH) map for human chromosome 21q was constructed at the Stanford Human Genome Center (see Stewart et al. 1997). Of 66 loci on this map, 33 were polymorphic and common to the genetic map in Fig. 1. These loci spanned a total of 2008 centiRays (cR) and showed total colinearity with the meiotic map order. Intermarker physical distances, both in $\mathrm{cR}$ and $\mathrm{kb}$, are provided in Table 1 . A correlation analysis shows high agreement between $\mathrm{cR}$ and $\mathrm{kb}$ distances with correlation coefficient 0.51 and a conversion rate of $18 \mathrm{~kb} / \mathrm{cR}$.

To quantify the relationship between genetic and physical distance, a normalized statistic, analogous to $\varphi$, can be used. However, in the genetics literature, it has been customary to compare physical distance per unit map distance. To reduce the effect of statistical fluctuations, and as outlined for $\varphi$ comparisons, we estimate the $\mathrm{kb} / \mathrm{cM}$ value in overlapping intervals spanning $15 \mathrm{cM}$. For 21q, the genetic map $(80.1 \mathrm{cM}$ in females; $54.3 \mathrm{cM}$ in males) and physical map (33,632 kb) was common between markers D21S215 and D21S1446. We observed a $420 \mathrm{~kb} / \mathrm{cM}$ ratio in females and a $620 \mathrm{~kb} / \mathrm{cM}$ ratio in males. The variation in these rates across the $21 \mathrm{q}$ map is shown in Fig. 2B.

\section{Interference}

Each of the two chromosomes from each CEPH offspring was examined to reveal the number and locations of each recombination event (exchange). The number of exchanges can be underestimated, giving a false impression of positive interference, unless informative markers have sufficient density along the $21 \mathrm{q}$ arm. We calculated, conservatively, assuming the Haldane map function, that every exchange could be detected with probability $99 \%$ or greater if an interval (marked by informative markers) was $15 \mathrm{cM}$ or smaller; each such interval was termed informative. For each meiosis, we determined the fraction of its total genetic length that was informative and chose only chromosomes with $90 \%$ or greater coverage for subsequent analysis. There were 186 maternally inherited and 160 paternally inherited informative chromosomes.

The observed exchange distribution, numbers of male and female meioses with $0-2+$ exchanges (Table 2), can be compared with various assumptions of interference. It is wellknown that given the chiasma count distribution, $\mathrm{c}_{\mathrm{j}}$ being the proportion of $\mathrm{j}$ chiasmata events $\left(\Sigma c_{j}=1\right)$, the expected proportion of $\mathrm{i}$ exchange events $\left(\mathrm{E}_{\mathrm{i}}\right)$ is given by:

$$
E_{i}=\sum_{i}\left(\begin{array}{l}
j \\
i
\end{array}\right)(1 / 2)^{j} c_{j}
$$

If chiasma interference is absent then the $c_{j}$ values arise from a Poisson distribution with mean $2 \omega$, where $\omega$ is the map distance in Morgans. Under this assumption, the expected proportion of $i$ exchange events $E_{i}$ is given by:

$$
E_{i}=\frac{e^{-\omega} \omega^{i}}{i !}
$$

The expected numbers of exchanges can also be directly computed from previous empirical observation of chiasma counts in human male meioses for 21q by Laurie and Hulten (1985). All comparisons of observed to expected numbers used a standard contingency $\chi^{2}$ test.

Positive chiasma interference on $21 \mathrm{q}$ can arise from two distinct effects: reduction in the numbers of double exchanges (see above) and nonrandom placements of the double exchanges. We used empirical permutation tests to assess the observed distribution of map distances between double exchanges versus expected values. To generate expected values we computed the distance between two randomly chosen single exchanges; this process was repeated 25,000 times and for maternal and paternal meioses separately.

\section{Empiric Map Function}

We computed an empiric map function by estimating the recombination value and map distance for all marker locus pairs ( $i, j)\left(i=1, \ldots, k, j>i\right.$ and $k=$ number of markers) $\hat{\omega}_{i j}$ was calculated as the sum of the estimated map distances of all comprehensive marker intervals between the specific pair of markers, and the recombination value $\hat{\theta}_{\mathrm{ij}}$ was estimated by:

$$
\hat{\theta}_{\mathrm{ij}}=\frac{\mathrm{n}_{\mathrm{odd}}}{\mathrm{N}_{\mathrm{ij}}}
$$

where $\mathrm{n}_{\text {odd }}$ is the number of offspring chromosomes with an odd number of exchanges between $i$ and $j$ and $N_{i j}$ is the total number of informative offspring chromosomes. We ignored data from locus pairs with fewer than 20 informative meioses. 
The map function comprised data on 1004 maternal locus pairs and 1016 paternal locus pairs. For simplicity, we chose to represent the function in units of $5 \mathrm{cM}$. Consequently, we replaced all recombination frequency values falling into a class by computing a weighted average using the weighting factor:

$$
A\left(\hat{\theta}_{i j}\right)=\frac{N_{i j}}{\hat{\theta}_{i j}\left(1-\hat{\theta}_{i j}\right)}
$$

with final weighted $\hat{\theta}^{*}$ for that interval being:

$$
\hat{\theta}^{*}=\frac{\sum_{i} A\left(\hat{\theta}_{i j}\right) \hat{\theta}_{i j}}{\sum_{i} A\left(\hat{\theta}_{i j}\right)} .
$$

The gender-specific empiric map functions are shown in Fig. 3.

\section{ACKNOWLEDGMENTS}

We thank Marc Halushka, Minerva Carrasquillo, and Haiming Chen for genotype and radiation hybrid marker data, and Drs. Tara Matise, Terry Hassold, and Hunt Willard for constructive comments during this study. This work was supported by the following research grants: E.C. grants GENE-CT93-0015 and BMH4-CT96-0554 to the European Chromosome 21 Consortium (M.B.P.), Jacob Madsens and Hustru Olga Madsens Fond (M.B.P.), Else og Mogens Wedell-Wedellsborgs Fond (M.B.P.), Smedemester Niels Hansen og hustru Johanne f. Frederiksen's Legat (M.B.P.), Brodrene Hartmanns Fond (M.B.P.), Kirstine Fonden (M.B.P.), Kong Christian den Tiendes Fond (M.B.P.), Lily Benthine Lunds Fond (M.B.P.), National Institutes of Health (NIH) grant HG00468 (S.E.A.), Swiss National Science Foundation grant 31.40500 .94 (S.E.A.), E.U. grant PL930015 (S.E.A.), funds from the University and Cantonal Hospital of Geneva (S.E.A.), and NIH grant HD28088 (A.C.).

The publication costs of this article were defrayed in part by payment of page charges. This article must therefore be hereby marked "advertisement" in accordance with 18 USC section 1734 solely to indicate this fact.

\section{REFERENCES}

Altschul S.F., Gish, W., Miller, W., Myers, E.W., and Lipman, D.J. 1990. Basic local alignment search tool. J. Mol. Biol. 215: 403-410.

Buetow, K.H. 1991. Influence of aberrant observations on high-resolution linkage analysis outcomes. Am. J. Hum. Genet. 49: 985-994.

Broman, K.W., Murray, J.C., Sheffield, V.C., White, R.L., and Weber, J.L. 1998. Comprehensive human genetic maps: Individual and sex-specific variation in recombination. Am. J. Hum. Genet. 63: $861-869$.

Chakravarti, A. 1991. Information content of CEPH family structures for linkage studies. Hum. Genet. 87: 721-724.

Chakravarti, A. and Lynn, A. 1999. Meiotic mapping in humans. In Genome analysis: A laboratory manual, Vol. 4. Mapping genomes (ed. B. Birren, et al.), pp. 1-69. Cold Spring Harbor Laboratory Press, Cold Spring Harbor, New York.

Collins F.S., Patrinos, A., Jordan, E., Chakravarti, A., Gesteland, R., and Walters, L. 1998. New goals for the U.S. Human Genome Project: 1998-2003. Science 282: 682-689.

Copeland, N.G., Jenkins, N.A., Gilbert, D.J., Eppig, J.T., Maltais, L.J., Miller, J.C., Dietrich, W.F., Weaver, A., Lincoln, S.E., Steen, R.G., et al. 1993. A genetic linkage map of the mouse: Current applications and future prospects. Science 262: 57-66.

Dausset, J., Cann, H., Cohen, D., Lathrop, M., Lalouel, J.-M., and
White, R. 1990. Centre d'Etude du Polymorphisme Humain (CEPH): Collaborative genetic mapping of the human genome. Genomics 6: 575-577.

Dib, C., Faure, S., Fizames, C., Samson, D., Drouot, N., Vignal, A., Millasseau, P., Marc, S., Hazan, J., Seboun, E., et al. 1996. A comprehensive genetic map of the human genome based on 5,264 microsatellites. Nature 380: 152-154.

Efron, B. 1982. The Jackknife, the Bootstrap and Other Resampling Plans. Society for Industrial and Applied Mathematics, Philadelphia, Pennsylvania.

Elston, R.C., Lange, K., and Namboodiri, K.K. 1976. Age trends in human chiasma frequencies and recombination fractions. I. Method for analyzing recombination fractions and applications to the ABO:Nail-Patella linkage. Am. J. Hum. Genet. 28: 69-76.

Haldane, J.B.S. 1931. The cytological basis of genetical interference. Cytologia 3: 54-65.

Handel, M.A. and Eppig, J.J. 1998. Sexual dimorphism in the regulation of mammalian meiosis. Curr. Topics Dev. Biol. 37: 333-358.

Handel, M.A. and Hunt, P.A. 1992. Sex-chromosome pairing and activity during mammalian meiosis. Bioessays 14: 817-822.

Hattori M., Fujiyama, A., Taylor, T.D., Watanabe, H., Yada, T., Park, H.-S., Toyoda, A., Ishii, K., Totoki, Y., Choi, D.-K., et al. 2000. The DNA sequence of human chromosome 21. Nature 405: $311-319$.

Hulten, M. 1974. Chiasma distribution at diakinesis in the normal human male. Hereditas 76: 55-78.

Hunt, P.A. and LeMaire-Adkins, R. 1998. Genetic control of mammalian female meiosis. Curr. Topics Dev. Biol. 37: 359-381.

Jackson, M.S., See, C.G., Mulligan, L.M., and Lauffart, B.F. 1996. A 9.75-Mb map across the centromere of human chromosome 10. Genomics 33: 258-270.

Jannsens, F.A. 1909. Spermatogenese dans les Batraciens. V. La theorie de la chiasmatypie, nouvelle interpretation des cineses de maturation. Cellule 25: 387-411.

Korenberg, J.R. and Rykowski, M.C. 1988. Human genome organization: Alu, lines, and the molecular structure of metaphase chromosome bands. Cell 53: 391-400.

Kosambi, D.D. 1944. The estimation of map distances from recombination values. Annals of Eugenics 12: 172-175.

Lamb, N.E., Freeman, S.B., Savage-Austin, A., Pettay, D., Taft, L., Hersey, J., Gu, Y., Shen, J., Saker, D., and May, K.M. 1996. Susceptible chiasmate configurations of chromosome 21 predispose to non-disjunction in both maternal meiosis I and meiosis II. Nat. Genet. 14: 400-405.

Lamb, N.E., Feingold, E., Savage, A., Avramopoulos, D., Freeman, S., Gu, Y., Hallberg, A., Hersey, J., Karadima, G., and Pettay, D. 1997. Characterization of susceptible chiasma configurations that increase the risk for maternal nondisjunction of chromosome 21. Hum. Mol. Genet. 6: 1391-1399.

Lander, E.S. and Green, P. 1987. Construction of multi-locus genetic linkage maps in humans. Proc. Natl. Acad. Sci. 84: 2363-2367.

Lasher, L., Reefer, J., and Chakravarti, A. 1991. Effects of genotyping errors on the estimation of chromosome map length. Am. J. Hum. Genet. 49: A369.

Laurie, D.A. and Hulten, M.A. 1985. Further studies on chiasma distribution and interference in the human male. Annals Hum. Genet. 49: 203-214.

Mahtani, M.M. and Willard, H.F. 1998. Physical and genetic mapping of the human X chromosome centromere: Repression of recombination. Genome Res. 8: 100-110.

Matise, T.C., Perlin, M., and Chakravarti, A. 1994. Automated construction of genetic linkage maps using an expert system (MultiMap): A human genome linkage map. Nat. Genet. 6: $384-390$.

McInnis, M.G., Chakravarti, A., Blaschak, J., Petersen, M.B., Sharma, V., Avramopoulos, D., Blouin, J.-L., Konig, U., Brahe, C., Matise, T.C., et al. 1993. A linkage map of human chromosome 21: 43 PCR markers at average intervals of $2.5 \mathrm{cM}$. Genomics 16: $562-571$.

Muller, H.J. 1916. The mechanism of crossing-over. Am. Naturalist 
Lynn et al.

50: $193-221,284-305,350-366,421-434$.

Nicolas, A. 1998. Relationship between transcription and initiation of meiotic recombination: Toward chromatin accessibility. Proc. Natl. Acad. Sci. 95: 87-89.

NIH/CEPH Collaborative Mapping Group. 1992. A comprehensive genetic linkage map of the human genome. Science 258: 67-86.

Petersen, M.B., Slaugenhaupt, S.A., Lewis, J.G., Warren, A.C., Chakravarti, A., and Antonarakis, S.E. 1991. A genetic linkage map of 27 markers on human chromosome 21. Genomics 9: 407-419.

Ross, L.O., Maxfield, R., and Dawson, D. 1996. Exchanges are not equally able to enhance meiotic chromosome segregation in yeast. Proc. Natl. Acad. Sci. 93: 4979-4983.

Rouyer, F., de la Chapelle, A., Andersson, M., and Weissenbach, J. 1990. An interspersed repeated sequence specific for human subtelomeric regions. EMBO J. 9: 505-514.

Shenkar, R., Shen, M.H., and Arnheim, N. 1991. Dnase I-hypersensitive sites and transcription factor-binding motifs within the mouse E beta meiotic recombination hot spot. Mol. Cell. Biol. 11: 1813-1819.

Sherman, S.L., Takaesu, N., Freeman, S.B., Grantham, M., Phillips, C., Blackston, R.D., Jacobs, P.A., Cockwell, A.E., Freeman, V., Uchida, I., et al. 1991. Trisomy 21: Association between reduced recombination and nondisjunction. Am. J. Hum. Genet. 49: $608-620$

Sherman, S.L., Petersen, M.B., Freeman, S.B., Hersey, J., Pettay, D., Taft, L., Frantzen, M., Mikkelsen, M., and Hassold, T.J. 1994 Non-disjunction of chromosome 21 in maternal meiosis I: Evidence for a maternal age-dependent mechanism involving reduced recombination. Hum. Mol. Genet. 3: 1529-1535.

Stewart, E.A., McKusick, K.B., Aggarwal, A., Bajorek, E., Brady, S., Chu, A., Fang, N., Hadley, D., Harris, M., Hussain, S., et al. 1997. An STS-based radiation hybrid map of the human genome. Genome Res. 7: 422-433.

Tanzi, R.E., Haines, J.L., Watkins, P.C., Stewart, G.D., Wallace, M.R.,
Hallewell, R., Wong, C., Wexler, N.S., Conneally, P.M., and Gusella, J.F. 1988. Genetic linkage map of human chromosome 21. Genomics 3: 129-136.

Tanzi, R.E., Watkins, P.C., Stewart, G.D., Wexler, N.S., Gusella, J.F., and Haines, J.L. 1992. A genetic linkage map of human chromosome 21: Analysis of recombination as a function of sex and age. Am. J. Hum. Genet. 50: 551-558.

Wallace, B.M. and Hulten, M.A. 1985. Meiotic chromosome pairing in the normal human female. Annals Hum. Genet. 49: 215-226.

Warren, A.C., Chakravarti, A., Wong, C., Slaugenhaupt, S.A., Halloran, S.L., Watkins, P.C., Metazotou, C., and Antonarakis, S.E. 1987. Evidence for reduced recombination on the nondisjoined chromosome 21 in Down syndrome. Science 237: 652-654.

Warren, A.C., Slaugenhaupt, S.A., Lewis, J.G., Chakravarti, A., and Antonarakis, S.E. 1989. A genetic linkage map of 17 markers on human chromosome 21. Genomics 4: 579-591.

Weissenbach, J., Gyapay, G., Dib, C., Vignal, A., Morissette, J., Millasseau, P., Vaysseix, G., and Lathrop, M. 1992. A second-generation linkage map of the human genome. Nature 359: 794-801.

White, M.A., Wierdl, M., Detloff, P., and Petes, T.D. 1991. DNA-binding protein RAP1 stimulates meiotic recombination at the HIS4 locus in yeast. Proc. Natl. Acad. Sci. 88: 9755-9759.

White, M.A., Detloff, P., Strand, M., and Petes, T.D. 1992. A promoter deletion reduces the rate of mitotic, but not meiotic, recombination at the HIS 4 locus in yeast. Curr. Genet. 21: 109-116.

White, M.A., Dominska, M., and Petes, T.D. 1993. Transcription factors are required for the meiotic recombination hotspot at the HIS4 locus in Saccharomyces cerevisiae. Proc. Natl. Acad. Sci. 90: $6621-6625$.

Received February 24, 2000; accepted in revised form July 12, 2000.

\section{Genome Research}




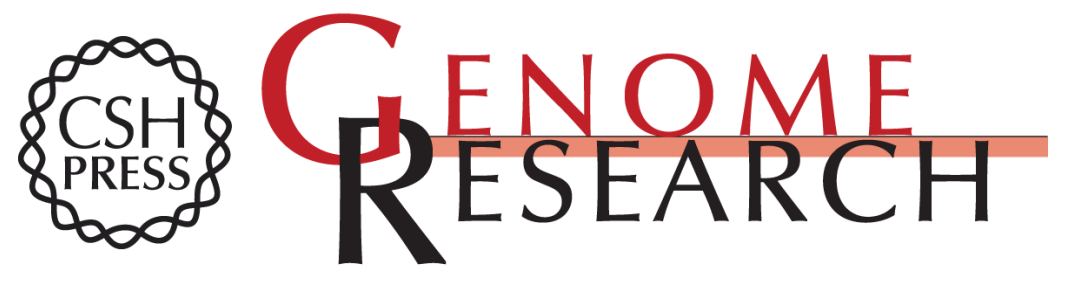

\section{Patterns of Meiotic Recombination on the Long Arm of Human Chromosome 21}

Audrey Lynn, Carl Kashuk, Michael B. Petersen, et al.

Genome Res. 2000 10: 1319-1332

Access the most recent version at doi:10.1101/gr.138100

Supplemental Material

References

License

Email Alerting Service
http://genome.cshlp.org/content/suppl/2000/08/27/10.9.1319.DC1

This article cites 45 articles, 12 of which can be accessed free at: http://genome.cshlp.org/content/10/9/1319.full.html\#ref-list-1

Receive free email alerts when new articles cite this article - sign up in the box at the top right corner of the article or click here.

\section{Affordable, Accurate Sequencing.}

To subscribe to Genome Research go to: https://genome.cshlp.org/subscriptions 